\title{
Gestão Compartilhada da Educação: a Experiência Catarinense
}

\author{
Jarbas José Cardoso
}

Universidade do Estado de Santa Catarina (Udesc)

Objetiva socializar algumas experiências de gestão compartilhada que a Associação dos Administradores Escolares de Santa Catarina (AAESC) vem desenvolvendo em diversas regiões, em parceria com a Secretaria de Estado da Educação, secretarias municipais da educação, universidades e outros segmentos representativos da sociedade civil, bem como pretende expressar, com clareza, o envolvimento da AAESC com a qualidade da escola pública, tendo como mediação a gestão compartilhada, permitindo que tanto a associação como os educadores catarinenses possam propor alternativas práticas de administração do projeto pedagógico. Inicia com um breve histórico da AAESC, seguido da discussão dos pressupostos teóricos preliminares e da apresentação das experiências em andamento; ao final, são feitas algumas considerações gerais.

\section{Breve histórico}

ORIGEM

Na organização política de uma categoria de trabalho e na formação de uma associação, é fácil definir com clareza o mérito de quem efetivamente conseguiu expressar o movimento dos profissionais envolvidos ou de quem foram os primeiros a levantar as bandeiras sociopolíticas e as de luta da categoria. Entretanto, é possível localizar fatos e épocas mais expressivos na aglutinação de idéias e vontades para a concretização da associação. 
Entre esses fatos e épocas, que contribuíram, decisivamente, para a organização dos administradores escolares em Santa Catarina, destacamse a consciência da importância de sua atuação e a insatisfação com relação às suas funções no processo educacional; os cursos de especialização e as atividades de extensão da Universidade Federal de Santa Catarina e de outras instituições de ensino superior de Santa Catarina; as outras associações de profissionais da educação; e a elaboração participativa do Plano Estadual de Educação, "Democratização da Educação: uma opção dos catarinenses".

Associando esses fatores, os administradores escolares, coordenados por um pequeno grupo de profissionais, reuniram-se em Itajaí e fundaram a Associação dos Administradores Escolares de Santa Catarina (AAESC), aos 18 de julho de 1984, e formaram a primeira diretoria para a organização da associação. A primeira diretoria procurou consolidar a idéia da formação de uma associação e mobilizar os administradores escolares de Santa Catarina para a organização e a corporificação da AAESC. Os primeiros passos tomados relacionaram-se ao registro da associação em cartório e a elaboração dos estatutos.

A segunda diretoria, a primeira eleita nas formas do estatuto, teve como atribuições fundamentais: dar caráter jurídico à associação, através do registro de seu estatuto; ampliar o reconhecimento pelos órgãos públicos; implantar núcleos regionais; ocupar o seu espaço na Comissão de Implantação do Plano Estadual de Educação; divulgar e lutar pela concretização das definições do Documento de Itajaí.

Nessa gestão, a AAESC conquistou seu reconhecimento como entidade legal e foi reconhecida como associação legítima de uma categoria de educadores, pela comissão encarregada de fiscalizar e acompanhar a implantação do Plano Estadual de Educação na SEC, aceitando, em decorrência, sua representação nessa comissão. A AAESC, a partir de então, indicou dois membros, um titular e um suplente, para participarem dessas atividades. 
A terceira diretoria continuou as atividades de mobilização e de luta, com base no documento de Itajaí. Entre suas atividades se destaca a realização do I Simpósio Catarinense de Administração da Educação, realizado em Florianópolis, de 6 a 10 de novembro de 1989. Nesse simpósio, foi elaborado e aprovado em assembléia o $2^{\circ}$ Documento da AAESC, no qual os administradores escolares de Santa Catarina se posicionaram com relação a aspectos político-administrativos.

\section{EXPANSÃO}

A partir de 1989, a AAESC, na continuidade de sua evolução histórica, experienciou a ampliação e a expansão de sua identidade, do trabalho em equipe, com ações participativas efetivas, procurando integrar nelas todos os seus associados. Logo no início desse período, a diretoria organizou o espaço e a infra-estrutura para as atividades da associação, alugando uma sala no Edifício Dias Velho, no centro de Florianópolis.

As atividades da AAESC culminavam na realização anual de simpósios. No segundo simpósio, em 1990, e no terceiro, em 1991, contaram com a participação de, aproximadamente, 160 sócios. A tônica inovadora desses simpósios foi a metodologia de trabalho. Foi proporcionado aos participantes trazerem suas experiências e documentos escritos por eles, que subsidiavam ampla discussão e elaboração de documentos em grupo. Os documentos produzidos eram então analisados por especialistas, para impulsionar a melhoria do trabalho escrito pelos grupos. Esse trabalho, dinâmico e participativo, exigiu o comprometimento de todos e culminou com a produção de um documento em cada simpósio, expressando o pensamento do grupo.

\section{COMPROMISSO COM O PROJETO PEDAGÓGICO}

A associação continuou no seu esforço de buscar experiências e metodologias alternativas para efetivamente mudar o concreto da prática 
educativa, em especial de sua gestão. Cobra, estimula, incentiva e apóia experiências de gestão democrática, participativa ou compartilhada. Para tanto, na historia da AAESC, a temática dos simposios teve uma progressiva evolução. O primeiro caracterizou-se como um encontro com palestras e debates, no qual um grupo de associados escreveu um documento, apresentado, debatido e aprovado na assembléia do evento. Do segundo ao sétimo simpósio, todos os participantes contribuíram com escritos, nos debates e na elaboração coletiva dos documentos. A temática evoluiu no segundo encontro, na busca de atingir a prática concreta, iniciando com a temática de participação na gestão da educação; no terceiro, a AAESC posicionou-se diante da política e da prática de descentralização do ensino em Santa Catarina; no quarto, foram discutidas e apresentadas sugestões concretas para a gestão compartilhada na elaboração, execução e avaliação do Projeto Político-pedagógico na Escola; no quinto e sexto, o eixo temático foi a gestão do ato pedagógico, tanto na de sala de aula como na unidade escolar; e no sexto simpósio vimos a avaliação com seus mitos e desafios.

Nos três últimos simpósios (1992, em Criciúma; 1993, em Caçador e 1994, em Chapecó), a AAESC concentrou esforços na discussão sobre o ato pedagógico, e foram elaborados, coletivamente, documentos pelos participantes dos eventos. Portanto, hoje os educadores catarinenses da rede pública, especialmente do sistema estadual, têm em mãos um referencial teórico sobre a especificidade e as implicações do ato pedagógico, para que consigamos atingir a tão propalada qualidade de ensino em nível de $1^{\circ}$ grau. Partindo-se do pressuposto que nesses simpósios já teríamos aprofundado razoavelmente as questões teóricas sobre o ato pedagógico, no sétimo simpósio concentramos esforços sobre a avaliação, seus mitos e desafios, relacionando-a com a gestão em nível de uma unidade escolar.

Neste breve histórico da AAESC, fica caracterizado a sua preocupação constante com os administradores escolares, em especial com sua qualificação permanente, para que possam enfrentar, com competência, os desafios da função em nível de unidade escolar, visando à melhoria da qualidade do ensino de $1^{\circ}$ grau. Portanto, acreditamos que, 
nos últimos seis anos, uma das iniciativas mais promissoras e produtivas é, sem dúvida, a oportunidade de discussão e de elaboração de documentos por todos e cada um dos participantes dos simpósios. Esta prática concreta exige uma efetivação compartilhada entre os estudiosos do assunto e entre os agentes de escolas ou de instâncias administrativas. Esse compromisso com o pedagógico auxilia na superação entre quem pensa e quem faz acontecer $\mathrm{o}$ ato pedagógico no dia-a-dia de uma unidade escolar.

\section{Gestão da educação: pressupostos preliminares}

A sociedade brasileira, a partir da redemocratização do País, passou por um processo de reordenamento nos campos social, político e econômico. Esse reordenamento está expresso na nova Constituição, promulgada em 1988. No campo educacional, do ponto de vista das formulações legais, houve vários avanços, entre eles a garantia de gestão democrática no ensino público (Artigo 206; IV). Esse dispositivo constitucional procura assegurar o caráter democrático do ensino público de tal forma que as instituições públicas possam criar uma cultura político-educativa de exercício do princípio e da prática democrática no seu cotidiano.

Os princípios educacionais definidos pela Constituição foram amplamente discutidos e aprofundados por ocasião da elaboração da Lei de Diretrizes e Bases da Educação Nacional (LDB), aprovada pela Câmara Federal em 13 de maio de 1993 (Projeto de Lei $\mathrm{n}^{\circ}$ 1.258-C, de 1988). Este projeto sofreu inúmeras alterações, além da entrada do projeto do senador Darcy Ribeiro, que foi fundido com a Proposta Cid-Sabóia, hoje em tramitação no Congresso Nacional. Nessa proposta em tramitação, prevê-se a reorganização do sistema educacional e, por conseguinte, da própria escola.

Espera-se que neste periodo de transição entre a atual LDB e a próxima sejam desenvolvidas políticas que fortaleçam a atuação da sociedade civil para a construção de uma gestão democrática. Nesse 
contexto, as instituições educacionais têm como tarefa a rediscussão de sua prática, o significado de seu trabalho pedagógico e a forma de gestão a ser desenvolvida nas escolas. Na rediscussão e na revisão das práticas pedagógicas e das formas de gestão, constituir-se-á um ponto importante a necessidade de se pensar sobre a gestão do público, a partir de uma concepção democrática. A concepção de gestão da esfera pública, com base nos pressupostos democráticos e na participação da sociedade civil, fortalece o caráter público do Estado e de suas instâncias. Essa perspectiva se contrapõe à privatização da esfera pública e à apropriação do público pelos interesses privados. Nas instituições públicas, a gestão com base nos princípios democráticos recoloca a questão da natureza do poder, suas formas, e a possibilidade concreta de exercê-lo no processo democrático da ação coletiva.

Uma reflexão que está se processando no campo educacional refere-se à passagem de uma administração mais centrada na concepção autoritária para uma administração centrada nos princípios democráticos. Esse processo demanda não só uma mudança no conceito de administração e de gestão, mas, especialmente, uma mudança no enfoque teórico e no conteúdo da administração e da própria natureza e prática social da escola. Os conceitos de democracia e de prática democrática precisam ser compreendidos e interpretados no interior da escola para, a partir daí, estabelecer um processo de gestão que fundamentalmente esteja vinculado aos objetivos pedagógicos, políticos e culturais da escola.

A concepção de gestão, incorporando os princípios democráticos, constitui um aprendizado que se processa no nível das instituições sociais, que se expressa por suas práticas políticas e culturais. Sociedade e escola são dialeticamente constituídas. A escola expressa e contradiz as relações sociais mais amplas.

O conceito e a prática de gestão democrática ainda não estão suficientemente desenvolvidos nas organizações e nas instituições educacionais. Tanto o conceito de gestão quanto o de democracia não se 
originaram no interior da escola. No entanto, a escola, como campo privilegiado de intervenção política e ideológica, traz, na sua essência pedagógica, a possibilidade de construção de novos paradigmas e práticas que priorizem a via democrática em si e na sociedade.

Dessa forma, o sentido democrático empregado para qualificar a condução de um processo de gestão está intimamente ligado aos valores da sociedade, da cultura, da escola e, fundamentalmente, às concepções de cidadania e de saber, que se promove para esse exercício de transformação da escola e da sociedade. Nesse sentido, não se pode desvincular a gestão democrática do processo pedagógico educativo mais amplo. A escola educa e forma o cidadão por suas relações pedagógicas.

Uma administração desse tipo, ao se efetivar como prática democrática de decisões, deve ser capaz de garantir a participação das comunidades interna e externa, a fim de que assumam o papel de coresponsáveis no projeto pedagógico. Em conseqüência, esta prática produz resultado pedagógico imediato e concreto, mais seguro e garantido do que o mero discurso sobre a necessidade democrática. A conclusão encontra seu pressuposto na afirmação de que é na prática que se gesta a consciência. Assim, através da prática desse processo administrativo, os envolvidos vivenciam as situações de cidadania próprias da dinâmica social e o papel do cidadão nessa dinâmica. Num processo colegiado, assinalase, ainda, a ênfase dada ao trabalho cooperativo e solidário indispensável à vida em sociedade. Se a administração participativa visa desenvolver um projeto educacional único e solidário, então sua essência é a cooperação. Nessa perspectiva, esse processo de administração se vincula intrinsecamente ao cumprimento da função social e política da educação escolar, que é a formação do cidadão participativo, responsável, crítico e criativo, através da produção e da socialização do saber historicamente acumulado pela humanidade.

A gestão democrática passa pela democratização da escola, pela natureza social da escola; não se restringe apenas aos processos transparentes e democráticos ligados à função administrativa. Não é possível uma escola 
autoritária desenvolver uma gestão democrática. Nesse sentido, a gestão democrática tem uma dimensão exógena e endógena. A primeira está ligada à função social da escola, à sua vocação democrática no sentido de democratizar o conhecimento produzido e socializado por ela. A segunda refere-se à forma de organização interna da escola, contemplando os processos administrativos, a participação tanto da comunidade escolar como da sociedade civil nos projetos pedagógico, político e administrativo da escola, ou seja, à forma como é administrada a escola. A concepção de gestão democrática não tem sido interpretada com base na totalidade do processo educativo e em seu significado político-social. Em muitos casos, a idéia de gestão fundamentada nos princípios e valores democráticos tem sido interpretada de forma parcial, ou seja, tomandose fatos isolados do processo de gestão como determinantes democráticos. Um exemplo que se coloca é a forma de escolha de diretores escolares, por meio de eleições. Essa forma, sem dúvida nenhuma, constitui um elemento importante de descentralização do poder da esfera central e de construção da autonomia da escola. O processo eletivo representa uma dimensão democrática importante. No entanto, não se pode tomar como determinante de gestão democrática apenas a forma de escolha do diretor por meio de processo eletivo. Esse processo constitui, sem dúvida, uma parte importante de construção concreta da cultura democrática. Mas, por si só, não assegura a gestão democrática, visto que a gestão constitui um processo pedagógico e apresenta um caráter dinâmico, dialético e que se dá no movimento político-administrativo da escola. $\mathrm{O}$ processo de gestão democrática constrói-se no interior da escola, na correlação de forças entre o instituído politicamente e o construído democraticamente.

A construção de um processo de gestão centrado nos valores e princípios democráticos é tarefa política e educativa da escola, que representa uma das mais importantes e essenciais atividades públicas e constitui locus de formação do cidadão como um ser social-histórico e um sujeito de 
relações. O trabalho como princípio educativo é inerente ao processo pedagógico da escola. Nesse sentido, não existem fórmulas de gestão democrática; ela se constrói no processo político e cultural da escola.

A gestão democrática não se limita somente à área administrativa. Pressupõe autonomia administrativa e financeira, assim como autonomia para que cada escola possa construir seu próprio projeto político-pedagógico e estabelecer seu próprio sistema de avaliação. Nesse sentido, a escola tornase democrática para sua essência pedagógica, traduzida por seu caráter público, pelas novas relações sociais que estabelece, pela democratização das decisões e, essencialmente, pela formação para a cidadania.

A concretização desse tipo de administração insere-se no contexto de uma concepção democrática de administração. Seu pressuposto fundamental é o de que a estratégia para a produção de uma forma qualitativa de tomada de decisões, no interior da escola, e, conseqüentemente, na sociedade, é a da participação co-responsável. A participação favorece a experiência coletiva ao efetivar a socialização de decisões e a divisão de responsabilidades. Ela afasta o perigo das soluções centralizadas e dogmáticas desprovidas de compromisso com os reais interesses da comunidade escolar da sociedade civil organizada. A participação constituise, pois, elemento básico de integração social democrática. Participação e democracia têm, assim, uma significação indissociável. Nesse contexto, é que se deve considerar a proposta da prática compartilhada de administração como uma forma qualitativa de vida escolar, baseada na conjunção de liberdade e co-responsabilidade nas decisões sobre a concepção do projeto pedagógico.

Portanto, a administração compartilhada pode constituir-se numa possibilidade de prática pedagógica aos envolvidos no processo, permitindo, talvez, concluir que essa prática administrativa contribua para a recuperação da função social da escola. Pois, ao democratizar as relações que se desenvolvem em seu interior, exigindo que a comunidade interna em conjunto com a comunidade externa participem da análise, discussão e deliberação a respeito da proposta educativa a ser concretizada, torna-se claro que essa administração possibilita mediar uma prática pedagógica qualitativamente 
adequada às necessidades e aos interesses das camadas populares, atual clientela majoritária da escola pública de $1^{\circ}$ grau. A administração democrática, ao se firmar na decisão coletiva, constitui-se em efetivo espaço de comprometimento dos representantes da comunidade interna e externa com o projeto pedagógico elaborado de forma compartilhada. A seguir, graficamente, será apresentada a idéia de gestão compartilhada na construção colegiada do projeto pedagógico para a escola pública.

\section{Figura 1 - Esquema de gestão compartilhada}

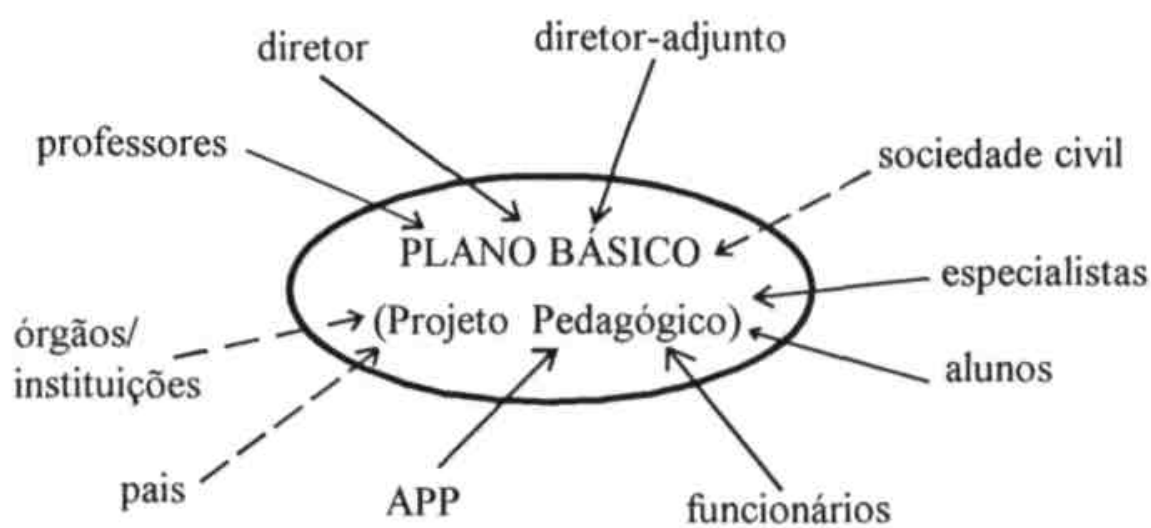

É exatamente nesse processo participativo que poderá ir se consolidando uma proposta de escola mais democrática, visando à construção de uma nova ordem social. Nessa perspectiva, a tarefa dos agentes educativos (direção, especialistas e professores) implica, em primeiro lugar, que eles compreendam que seu trabalho se estende ao compromisso com a totalidade do processo escolar, não se restringindo, por conseguinte, à sala de aula. Isso, por sua vez, exige que eles percebam a dimensão político-pedagógica de seu trabalho e o significado social de 
se co-responsabilizar pela definição do projeto pedagògico a ser assumido pela escola e por suas possíveis conseqüências. Em segundo lugar, que eles, em conjunto com a sociedade, garantam a efetivação de uma prática pedagógica progressista que leve ao pleno exercício da cidadania. Isso significa que eles devem procurar garantir aos seus alunos a produção e a posse sistemática do saber científico historicamente acumulado, sem esquecer as experiências de vida e a realidade social daqueles a quem devem educar. Este aspecto tem o mérito de elevar o nível de consciência crítica dos alunos e de introduzi-los na atualidade histórica e social de sua época, possibilitando-lhes uma atuação consciente e competente na transformação da História.

Isso exige uma escola emancipadora que propicie aos alunos, além das condições de domínio do saber sistematizado, o efetivo exercício democrático de participação nas decisões da vida escolar. E, através do desenvolvimento desse espírito cooperativo, os agentes educativos estarão contribuindo para que os educandos se convertam em elementos ativos de transformação da sociedade. Neste particular, cabe à escola desenvolver o conhecimento enquanto formação do homem culto; para tanto, faz-se necessário uma escola como facilitadora, onde o aluno desenvolva aptidões cognitivas, que servirão para sua caminhada ao longo da vida.

Nesse sentido, parece estar implícita a importância da administração democrática, não apenas como instância de natureza administrativa, mas como mediação de uma prática pedagógica e política. Colocada nesses termos, essa administração é percebida como possibilidade de recuperação da função social da escola pública.

Qualquer unidade escolar que se utilize da gestão compartilhada como facilitadora da emancipação do cidadão e da universalização do trabalho intelectual exigirá mudanças no ato pedagógico expresso no projeto pedagógico, que fora elaborado em comum acordo entre agentes educativos e sociedade. Para tanto, faz-se necessário pensar e planejar um processo de implantação e implementação de uma administração compartilhada por unidade escolar, além das atuais experiências em andamento em cinco regiões do Estado de Santa Catarina. 


\section{Experiencias em andamento}

Tomando por base as preocupações teóricas e as reflexões anteriores, nesta parte serão apresentadas as ações concretas que visam operacionalizar uma gestão democrática na prática do dia-a-dia, em nível de unidade escolar. Existem inúmeras formas, procedimentos e experiências no País na tentativa de concretizar uma prática participativa na escola pública. Há experiências no plano das estruturas organizacionais de secretarias estaduais da educação, em Pernambuco, Minas Gerais, São Paulo etc, e, no plano das secretarias municipais de educação, em São Paulo, Maringá, Novo Hamburgo, Salvador etc. Outras experiências são no plano das unidades escolares em Contagem-MG, Rio de Janeiro, IjuíRS, Ceará, São Paulo, Belém e Santa Catarina.

Dentre todas as experiências obtidas por acesso a livros, revistas, artigos e relatos, até o presente, classifico a caminhada catarinense através da AAESC como um processo cuja origem e cujo desenvolvimento se diferenciam sobremaneira das experiências citadas acima, tanto pela natureza quanto pelo retorno imediato à construção de uma administração mais democrática da educação. A caminhada rumo às alternativas teóricometodológicas, à questão da administração escolar catarinense, encontrou resposta na AAESC, que procurou sistematizar e discutir as preocupações dos administradores, num fórum comum da categoria.

A partir de 1989, a AAESC, além de dar continuidade às tendências anteriores, nas três diretorias seguintes (1989-1991; 1991-1993 e 1993-1995), através dos simpósios anuais, implantou uma metodologia e uma dinâmica de produção coletiva de documentos nos próprios eventos. Segundo Wittmann (Wittmann, Cardoso, 1993, p.23), na história da AAESC, uma das iniciativas mais promissoras e produtivas é, sem dúvida, o trabalho coletivo de todos e de cada um dos participantes dos eventos, na elaboração coletiva de documentos. Esta prática concreta exige uma construção compartilhada entre os estudiosos do assunto e os agentes em nivel de escolar ou de instâncias administrativas. Este compartilhamento é uma experiência de superação entre quem pensa e quem faz a administração nossa de cada dia. 
Figura 3 - Metodologia da Construção Compartilhada

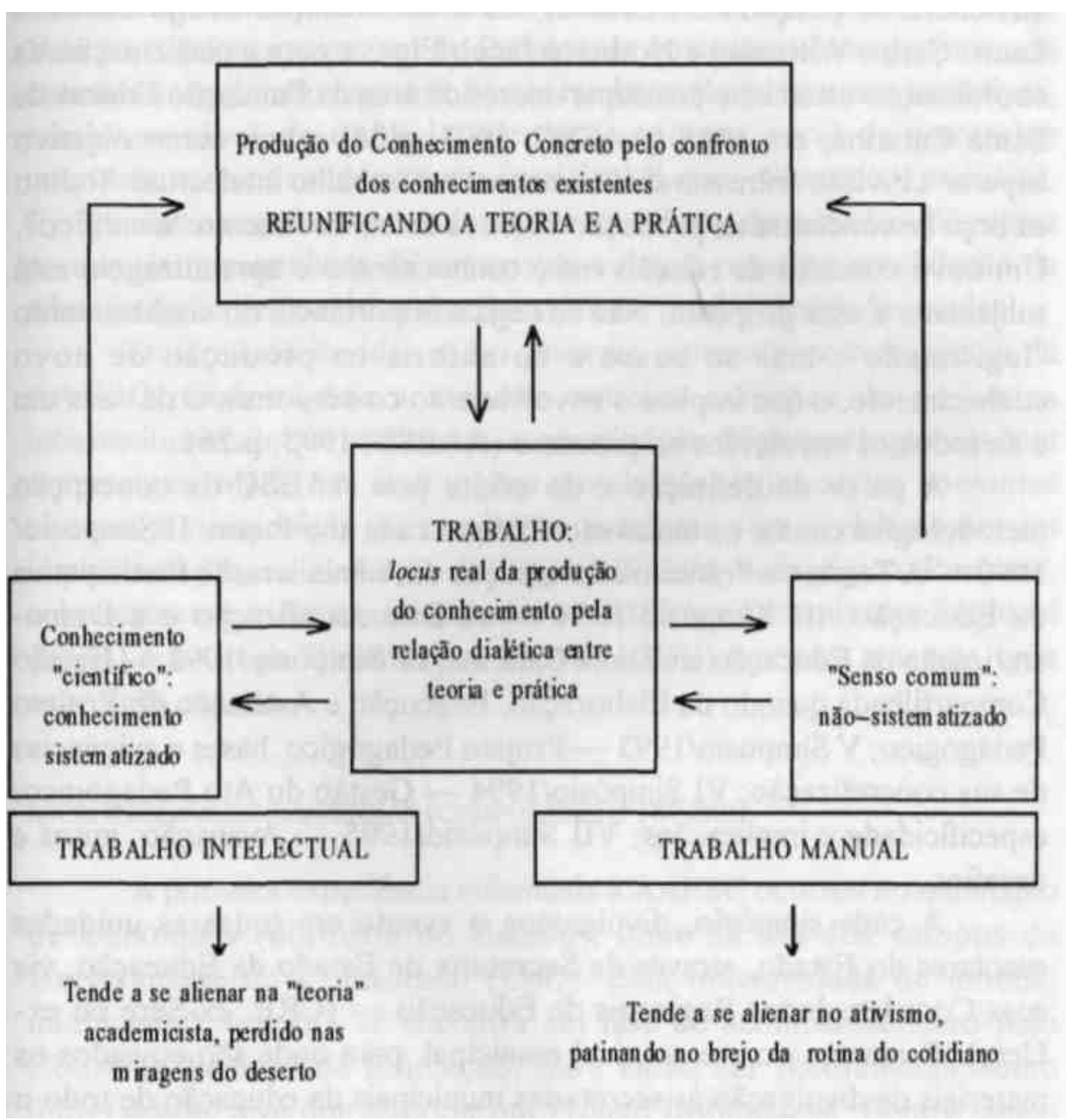

Fonte: Wittmann e Cardoso, 1993, p.23

R. bras. Est. pedag., Brasilia, v.76, n. 182/183, p.139-170, jan./ago. 1995 
Essa metodologia começou a ser construída coletivamente em atividades de pesquisa e extensão, sob a coordenação dos professores Lauro Carlos Wittmann e Norberto Jacob Etges e com a participação da coordenação estadual e dos supervisores de área da Fundação Educar de Santa Catarina, em 1985 (AAESC, 1993, p.26) e tem como objetivo superar a divisão entre o trabalho manual e o trabalho intelectual. Todo o esforço se concentra na produção coletiva de conhecimento "científico". Um novo conceito de relação entre conhecimento e aprendizagem está subjacente a essa proposta. Não se nega a importância do conhecimento "legitimado", mas se busca a co-autoria na produção de novo conhecimento, o que implica o envolvimento co-responsável de cada um e de todos os envolvidos no processo (AAESC, 1993, p.26).

A partir da definição e do aceite pela AAESC da concepção metodológica citada, os temas escolhidos a cada ano foram: II Simpósio/ 1990 - A Teoria e a Prática na Construção da Administração Participativa da Educação; III Simpósio/1991 — A Descentralização e a Democratização da Educação em Santa Catarina; IV Simpósio/1992 — Gestão Compartilhada quando da Elaboração, Execução e Avaliação do Projeto Pedagógico; V Simpósio/1993 — Projeto Pedagógico: bases e exigências de sua concretização; VI Simpósio/1994 — Gestão do Ato Pedagógico: especificidade e implicações; VII Simpósio/1995 - Avaliação: mitos e desafios.

A cada simpósio, divulgamos o evento em todas as unidades escolares do Estado, através da Secretaria de Estado da Educação, via suas Coordenadorias Regionais de Educação - (CRE, ex-Sere ou exUcre). O mesmo ocorre no nível municipal, para onde são enviados os materiais de divulgação às secretarias municipais da educação de todo o Estado. Embora o número de instituições ou escolas que se habilitam aos relatos não tenham sido tão expressivos, mesmo assim, nos últimos simpósios (1992, 1993, 1994 e 1995) foi possível ter uma panorâmica dos esforços de gestão democrática na educação em Santa Catarina. 
Hoje, de acordo com os relatos havidos nos simposios da AAESC, há cinco experiências em andamento (extremo-oeste, meio-oeste, noroeste, Vale do Itajaí e extremo sul do Estado), as quais têm como proposta de trabalho um processo regional. Foram também relatadas outras iniciativas, tanto em nível de unidade escolar como em nível de parcerias interinstitucionais ou de sistema municipal (Lages, Chapecó, Criciúma). É importante ressaltar que cada região se utilizou de métodos diferentes para iniciar a caminhada da construção coletiva rumo à consolidação da administração democrática da educação, no nível de unidade escolar.

Dos relatos havidos até o presente momento nos simpósios da AAESC, chamou-nos a atenção aqueles esforços de parcerias interinstitucionais que resultaram na constituição de grupos regionais com representatividade das instituições envolvidas, cujas ações conjuntas levaram à composição de comissões escolares para a elaboração, ou implementação, ou avaliação do Projeto Político-pedagógico. Portanto, sobre essas experiências estruturadas com o Grupo Dinamizador Regional (GDR) e o Grupo Dinamizador Escolar (GDE) faremos, a seguir, uma exposição sucinta.

\section{MICRORREGIÃO DE CANOINHAS (CAMPUS UNC E 18ª CRÊ)}

A primeira experiência informada à AAESC ocorreu no município de Canoinhas (noroeste do Estado), onde há um dos campus da Universidade do Contestado (UnC). Esta universidade de modelo multicampi ${ }^{1}$, que ora se encontra em fase de acompanhamento pelo Conselho Federal de Educação, para então ser reconhecida como universidade, teve que elaborar um Projeto Institucional. Dentre tantos

\footnotetext{
${ }^{\text {I }}$ A UnC, ao elaborar seu projeto de universidade para enviá-lo ao Conselho Federal de Educação, o fez concebendo um modelo multicampi, assim distribuído: Campus I — Caçador/sede da universidade; Campus II - Concórdia; Campus III — Canoinhas; Campus IV — Mafra; Campus V — Curítibanos.
} 
compromissos com a região, previu que em todos os seus campi haveria prioridade pelo ensino fundamental.

Com base nesse pressuposto, o Centro de Ensino Superior, através do curso de Pedagogia, programou para o $1^{\circ}$ semestre de 1993 um curso de extensão para qualificação dos docentes da Coordenadoria Regional de Educação. $\mathrm{O}$ curso teve a participação de 84 profisssionais da educação (diretores, um especialista escolhido e professores), correspondendo a 54 escolas da região.

A proposta do curso de 80 horas previu várias etapas, nas quais os participantes avançariam na elaboração do Projeto Político-pedagógico, culminando na montagem do documento norteador das ações administrativas e pedagógicas em cada unidade escolar, com educadores freqüentes ao curso. Ao término do curso foram programados novos encontros para acompanhamento e avaliação da implantação do projeto em cada escola. Em 1995, serão apresentados em Joinville os avanços e os obstáculos da caminhada nas escolas da referida região.

MICRORREGIÃO DE ITAJAÍ (13 ${ }^{\mathrm{a}}$ CRE, UNIVALI, SME E NÚCLEO COS ADMINISTRADORES ESCOLARES)

A segunda experiência foi encampada pela $13^{\mathrm{a}}$ Coordenadoria Regional de Educação (CRE, ex-Sere), pela Universidade do Vale do Itajaí (Univali) e pelo Núcleo dos Administradores Escolares da Foz do Rio Itajaí (Naefri), com a cooperação técnica da Udesc e da UFSC, através da AAESC. Os professores Lauro Carlos Wittmann (UFSC) e Jarbas José Cardoso (Udesc), a convite da $13^{\mathrm{a}} \mathrm{CRE}$, fizeram-se presentes numa reunião (17/03/93) com diretores e especialistas de todas as escolas da região. Após o término daquele dia de trabalho, optaram pela participação na experiência 12 escolas. Com base nisso, foi elaborado uma proposta de caminhada na região, a qual foi apresentada e aprovada pelos representantes das 12 escolas. A dinâmica aprovada previu a composição 
do Grupo Dinamizador Regional e do Grupo Dinamizador Escolar. O primeiro composto por três representantes da escola (direção, especialistas ou professor) e representantes da Univali, da $13^{\text {a }}$ CRE e do Naefri. O segundo seria constituído por três integrantes do regional, acrescido de pessoas da comunidade interna e externa à escola. Foram programados encontros mensais para troca de experiências entre as escolas, bem como para aprofundamento de temas específicos e replanejamento das ações para a continuidade da caminhada na escola.

Em setembro de 1993, no V Simpósio, em Caçador, o Grupo Dinamizador Regional elegeu uma equipe que elaborou um documento da caminhada na $13^{\mathrm{a}} \mathrm{CRE}$, fazendo relato da experiência naquele evento. Foram relatados cinco projetos: Planejamento Participativo de $\mathrm{I}^{\mathrm{a}}$ a $4^{\mathrm{a}}$ Série; Avaliação Participativa; Amor à Vida; Resgate dos Conteúdos e Integração Escola x Comunidade, que se encontravam na ocasião, sendo executados de forma colegiada em sete das 12 escolas envolvidas no processo.

Ao término do ano foi realizada uma avaliação da experiência, sendo esta aprovada pelos representantes das escolas. Posteriormente, houve também uma avaliação conjunta da $13^{\mathrm{a}} \mathrm{CRE}$ e da AAESC, ficando acertada a continuidade da experiência em 1994, com a tentativa de envolvimento de todas as escolas ligadas à Coordenadoria Regional. Em função dessa decisão e em face do aperfeiçoamento do processo em andamento, optou-se pela reestruturação formal da Comissão Regional, que deveria ser acrescida das secretarias municipais de educação da região, bem como pelo reforço de pessoal da $13^{\mathrm{a}} \mathrm{CRE}$ e da Univali para garantir o atendimento a todas as escolas da região. Atualmente permanecem na experiência 12 escolas, localizadas em municípios diferentes, algumas localizadas na zona rural, outras na zona urbana, a menor escola com 170 alunos e 20 funcionários e a maior com 2 mil alunos e 120 funcionários, que trocam experiências de gestão compartilhada entre si. No dia 15 de dezembro de 1994, aconteceu o último encontro do ano, quando se tratou da avaliação do trabalho de gestão compartilhada para a elaboração do 
Projeto Político-pedagógico nas escolas da região de Itajaí. Tratou-se também do planejamento das ações a serem desenvolvidas durante o ano letivo de 1995. Participaram da reunião representantes das unidades escolares, da $13^{\text {a }}$ CRE, da Univali, da AAESC/Udesc, do Naefri e da Secretaria Municipal da Educação de Penha.

Após a avaliação dos trabalhos desenvolvidos durante o ano letivo de 1994, os educadores presentes reivindicaram a continuidade do Projeto de Gestão Compartilhada na região, já que o mesmo tem trazido contribuição para a elaboração, execução e avaliação do Projeto Políticopedagógico na Unidade Escolar.

Em seguida, os participantes do encontro dividiram-se em grupos para discutirem subsídios para o desenvolvimento de ações em nível regional e escolar, visando à continuidade do trabalho de gestão compartilhada na região de Itajaí. Todos os subsídios discutidos foram aprovados pelos presentes que elegeram alguns representantes para posterior elaboração do documento, produto da reunião.

Foi eleito também um grupo denominado Comitê, para a apresentação do referido documento junto ao órgão regional de educação. A seguir, serão apresentadas as ações previstas pelo Grupo Dinamizador Regional (GDR), a serem implementadas em 1995.

\section{Nível regional O}

que fazer:

- Coordenar o projeto de gestão compartilhada na região;

- Divulgá-lo nas escolas;

- Ampliar o número de escolas que queiram participar do projeto;

- Ampliar o Grupo Dinamizador Regional, envolvendo representantes das escolas e demais segmentos;

- Constituir grupos de apoio para trabalharem nas escolas; 
- Acompanhar os trabalhos nas escolas;

- Proporcionar condições de troca de experiências entre as escolas;

- Representar a CRE no Grupo de Apoio Teórico (GAT) e no Grupo Gestor (GG);

- Avaliar as ações desenvolvidas;

- Elaborar calendário.

Como fazer:

— Encontro regional para divulgação do Projeto GC e ampliação do número de escolas participantes;

- Coordenação do Grupo Dinamizador Regional para troca de experiências entre as escolas;

- Coordenação das reuniões com os grupos de apoio, para estudos, avaliação e planejamento;

- Coordenação das visitas periódicas às escolas envolvidas, para assessoramento pelos grupos de apoio;

- Avaliação constante do processo mediante relato das experiências desenvolvidas dentro de um determinado tempo;

- Elaboração de relatórios que visem a documentar o trabalho em nível regional;

- Organização e fixação de calendário mediante a participação das instituições envolvidas.

Nível escolar

O que fazer:

- Implantar a gestão compartilhada na UE, visando à operacionalização das prioridades pedagógicas, com melhor aproveita mento dos recursos humanos, materiais e tecnológicos existentes; 
- Coordenar o Projeto de Gestão Compartilhada como meio de discussão do Projeto Político-Pedagógico na UE;

- Envolver a comunidade escolar nas discussões do PPP;

- Constituir o Grupo Dinamizador Escolar, envolvendo representantes de todos os segmentos da comunidade escolar;

- Representar a UE no GDR;

- Planejar ações que priorizem a relação entre professor e aluno, tanto na discussão da construção do conhecimento e da avaliação deste último como na forma de administração da escola como um todo;

- Elaborar relatórios do trabalho desenvolvido na UE;

- Trocar experiências com as escolas que participam do projeto;

- Participar da elaboração do calendário em nível regional;

- Elaborar calendário escolar.

Como fazer:

- Participação das UEs no encontro regional, para divulgação do Projeto de Gestão Compartilhada, visando à sua continuidade;

- Reunião da coordenação do projeto na UE, por segmentos da comunidade escolar;

— Reunião com toda a comunidade escolar, para a eleição dos representantes à formação do GDR;

- Planejamento de ações que visem à discussão, para a elaboração, execução e avaliação do PPP;

- Troca de experiência com outras UEs nas reuniões regionais;

- Reuniões periódicas de estudos e avaliação das ações desenvolvidas, para retomada do processo;

- Organização e fixação de calendário que corresponda às necessidades da UE;

- Elaboração de relatórios que visem documentar o trabalho desenvolvido em cada UE. 
Univali $\mathrm{O}$ que

fazer:

Pró-Reitoria de Extensão e Pesquisa

- Compromoter-se com a comunidade escolar da escola pública;

- Envolver representantes da comunidade escolar da escola pública e entidades de classe no Grupo Gestor, para o resgate da qualidade do ensino;

- Oferecer cursos para diretores, especialistas e professores, condizentes com a proposta pedagógica que atenda à demanda qualitativa do ensino;

- Oportunizar o estudo das teorias do conhecimento e como elas interagem no ato pedagógico;

- Acompanhar as experiências na escola e na região através de um Grupo de Assessoramento Teórico (GAT);

- Assessorar o GDR.

Como fazer:

- Atendimento à comunidade escolar da rede pública através da Pró-Reitoria de Extensão, Pesquisa e Pós-Graduação, envolvendo faculdades.

Extensão:

Odontologia - atendimento à comunidade;

Direito - estágio e atendimento;

Psicologia - estágio e atendimento através do SPA;

Fonoaudiologia - estágio e atendimento através do $\mathrm{CDH}$;

Jornalismo - jornal da gestão;

Filosofia - curso e assessoria pedagógica à comunidade escolar;

Enfermagem - estágios, palestras e orientações; 
Computação - instalação de hardware e software, Farmácia -

campanha de combate à verminose e atendimento laboratorial;

Pesquisa - diagnóstico sócio-econômico e cultural;

Registro científico das experiências em nível regional.

MICRORREGIÃO DE JOAÇABA — CAÇADOR (UNC, $14^{\mathrm{a}}$ CRE, SME, SINTE E NÚCLEO

DOS ADMINISTRADORES ESCOLARES)

Há também uma caminhada interessante no município de Caçador (meio-oeste), onde professores e alunos da escola pública têm, de forma integrada, em algumas disciplinas, elaborado e executado projetos de pesquisa, bem como redigido colegiadamente o relatório final. Tal esforço foi apresentado por um grupo de alunos, no V Simpósio da AAESC, em 1993. Pôde-se observar uma tentativa conjunta de construção do conhecimento, ou seja, um avanço em relação à mera transmissão do professor e à decoreba do aluno, que será cobrada em prova, em outro momento.

Motivados pelos relatos havidos no $\mathrm{V}$ Simpósio, foram programados inúmeros encontros em nível regional, oportunidade em que foi desenvolvida a seguinte programação: 1) exigências para a Ação Compartilhada (ter claro a função social da escola; ter claro o objeto da escola e a análise da estrutura organizacional); 2) montagem do Processo de Caminhada para a Gestão Democrática da Educação (modelos alternativos, estratégias operacionais). Disso culminou a constituição do Grupo Dinamizador Regional, em agosto de 1994. A partir dessa data, ocorreram vários encontros entre as 75 pessoas envolvidas no processo. No último encontro, nos dias $1^{\circ}$ e 2 de dezembro de 1994, foram avaliadas as atividades realizadas e planejada uma programação para 1995, do qual constam a elaboração e a entrega de documento-síntese da caminhada ao órgão regional de educação, por representantes do Grupo Dinamizador Regional. Após o contato com representantes da CRE, seria elaborado o planejamento (CRE, AAESC, Núcleo de Administradores de Caçador, 
UnC e Grupo Dinamizador Regional) das ações de continuidade da experiencia na região, tendo como atividades iniciais: 1) reunião com todos os diretores, diretores-adjuntos e especialistas; 2) visitas às escolas por município ou por municípios próximos para sensibilizar professores, alunos, funcionários e APPs; 3) plano de encontros de revitalização do Grupo Dinamizador Regional.

MICRORREGIÃO DE ARARANGUÁ (UNESC-FUCRI/IJNISUL, 15ª CRE, SME, SINTE E NÚCLEO DOS ADMINISTRADORES ESCOLARES)

Após o V Simpósio de Caçador, também a região do extremo sul do Estado despertou para a necessidade de iniciar uma caminhada em busca de alternativas para a administração da escola pública. Em meados de novembro de 1993, a convite da $15^{\text {a }}$ Coordenadoria Regional de Educação (ex-Sere), a AAESC fez-se presente numa reunião com todos os diretores gerais de escolas da região. Na ocasião, refletiu-se sobre a necessidade de pensar formas alternativas de gestão do ato pedagógico. Ao término do encontro, habilitaram-se 20 escolas das 44 presentes na reunião. Foi solicitado que cada diretor expusesse por escrito o estágio em que se encontrava sua escola em relação à democratização da administração, bem como se o mesmo pretendia participar da experiência, e de que forma pensava dar início à sua caminhada. Responderam a esta solicitação 15 das 20 escolas que em novembro haviam se apresentado para o desafio.

No dia 16 de dezembro de 1993, fizemos outra reunião com representantes (diretores ou especialistas ou professores) das 15 escolas. Ao término do encontro, ficou decidido pelos presentes que seriam programados três encontros no primeiro semestre de 1994. Desses encontros deveriam participar diretores, especialistas, professores, técnicos da $15^{\text {a }}$ CRE, representantes da Unesc/Fucri e Unisul e o Núcleo de Administradores do Vale do Araranguá, e que os temas prioritários seriam: Teorias do Conhecimento Pedagógico; Fundamentos da Proposta Curricular; Estrutura da Organização Escolar e Processo de Participação. 
Os referidos encontros aconteceram nos meses de abril, maio e junho, com a participação de 31 escolas e técnicos da $15^{\text {a }} \mathrm{CRE}$, perfazendo um total de aproximadamente 80 educadores. No último encontro, foi decidido em plenária a constituição de um Grupo Regional e de um Grupo Dinamizador Escolar para coordenação e o acompanhamento da experiência na região. No dia 14 de julho de 1994, foi instalado o Grupo Regional (composto por participantes dos três encontros, Undime, Sinte e Universidade Regional), bem como foram definidas e aprovadas as funções de coordenação e assessoria como imprescindíveis para garantir a implantação e a implementação da experiência na região. $\mathrm{Na}$ oportunidade, foram eleitos representantes dos segmentos constitutivos do grupo regional, para compor um grupo de trabalho com funções administrativas e operacionais em relação ao regional. Com base nessa estrutura organizacional regional e em cada escola (Grupo Dinamizador Escolar), serão programados encontros para troca de experiências e de revitalização da caminhada, conforme fez a região do Vale do Itajaí no ano de 1993. Esta região se encontra hoje atuando efetivamente em unidades escolares e no dia 18 de novembro de 1994 fez uma avaliação da caminhada em nível regional, bem como elaborou a programação para 1995: 1) montagem de relatório da experiência em 1994, com rol de reivindicações de continuidade do processo, a ser entregue ao órgão regional de educação; 2) reunião conjunta entre os novos diretores de escolas, a equipe da CRE e os membros antigos do GDR 3) reuniões de sensibilização e planejamento em cada escola da região (podendo a reunião ser por municípios próximos); 4) continuidade da discussão da gestão do ato pedagógico nos dias de estudos em cada escola.

MICRORREGIÃO DE SAO MIGUEL DO OESTE ( $12^{\mathrm{a}}$ CRE, INOESC, SME, SINTE E NÚCLEO

DOS ADMINISTRADORES ESCOLARES)

No ano de 1994, a $12^{\text {a }}$ CRE (ex-Sere) de São Miguel do Oeste (extremo oeste de Santa Catarina) aderiu ao desafio de implantar um processo de gestão democrática da educação na região. Para tanto, organizou dois eventos de 24 horas cada, sendo um executado em setembro e outro, 
em novembro deste ano. No encontro de setembro foi desenvolvida a seguinte programação: 1) exigências para a ação compartilhada (ter claro a função social da escola; ter claro o objeto da escola e a análise da estrutura organizacional escolar); 2) montagem de processo regional de caminhada para gestão democrática da educação (modelos alternativos e estratégias operacionais). Ao final do encontro, foi constituído o Grupo Dinamizador Regional e deste foram eleitos alguns representantes que compuseram o grupo de trabalho com funções administrativas e operacionais do processo regional, cabendo ao primeiro (GDR) a atribuição coordenadora e de assessoria às unidades escolares da $12^{\mathrm{a}} \mathrm{CRE}$.

Nos dias 28, 29 e 30 de novembro de 1994, houve o segundo encontro com as mesmas pessoas do evento de setembro. Nessa oportunidade, foi desenvolvida a seguinte pauta: 1) relato dos avanços e obstáculos da gestão democrática (nos níveis regional, municipal e escolar); 2) reflexões sobre a "mundialização" e a educação (leitura de mundo, que país é este e virada do milênio); 3) planejamento das ações para 1995. Os encontros objetivaram preparar teórica e tecnicamente em torno de 80 educadores (diretores, OE, SE, AE, professores, inspetores, técnicos da CRE, SME, comunidade civil organizada e representantes da Unoesc), para, posteriormente, como multiplicadores, implantarem e implementarem o processo de gestão democrática nas unidades escolares da região. Para 1995, o Grupo Dinamizador Regional definiu: 1) elaboração e entrega de documento ao órgão regional de educação; 2) visitas às escolas da região para constituir os grupos dinamizadores escolares; 3) constituição dos grupos dinamizadores municipais; 4) previsão de encontros de revitalização técnica dos grupos dinamizadores.

MICRORREGIÃO DE JOINVILLE ( $5^{\text {a }}$ CRE, SME, UNIVILLE, SINTE E NÚCLEO DOS ADMINISTRADORES ESCOLARES)

Mais recentemente, nos dias 10 e 11 de novembro de 1994, houve a mobilização de 135 educadores da $5^{\mathrm{a}} \mathrm{CRE}$ (ex-Sere), para iniciar estudos 
programação: 1) exigências para a ação compartilhada (ter clara a função da escola; ter claro o objeto da escola e análise da estrutura organizacional escolar); 2) montagem do processo regional de caminhada para a gestão democrática da educação. Como resultado concreto do encontro, foi constituído um grupo de trabalho com 15 pessoas (dois diretores; dois OEs, dois SEs, dois AEs, dois representantes municipais, dois representantes do Sinte e três técnicos da CRE), que irão programar novos eventos, com vistas a deflagrar o processo de democratização da educação na região norte do Estado.

Acredito que os informes confirmam a peculiaridade dos avanços pela melhoria da qualidade de ensino em relação a outras experiências citadas em nível nacional. Vejo que a caminhada catarinense parte do interesse de educadores que, associando-se às instituições governamentais, ou não universitárias, pretendem, em conjunto, discutir e construir os rumos de uma nova escola, que a sociedade brasileira está a exigir nesta virada do milênio.

Entendo, também, que esse esforço tenaz dos educadores catarinenses envolvidos nessa experiência, que têm o apoio irrestrito da AAESC, a qual tem contado com a cooperação significativa e essencial da Secretaria de Estado da Educação e das universidades catarinenses, dá algumas respostas às questões teóricas aludidas nos tópicos anteriores deste documento. Além do que, expressa uma vontade inconteste de aprender a fazer fazendo, o que só é possível à medida que se registra e se socializa a caminhada a tantos quantos se preocupam com a melhoria da qualidade do ensino de $1^{\circ}$ grau.

\section{Considerações finais}

$\mathrm{O}$ artigo procurou registrar uma recente e bem-sucedida iniciativa em prol da democratização da educação catarinense, ou seja, um esforço coletivo que tendo a gestão como facilitadora do ato pedagógico, contribua para a melhoria do ensino em nível de $1^{\circ}$ grau. O desenvolvimento do 
processo democrático, implementado nas experiencias citadas, pressupõe sua construção no cotidiano escolar, o que não dispensa a necessidade da reflexão permanente a respeito dos obstáculos e das potencialidades que se apresentam na realidade concreta.

Parece-me que ficou claro aos grupos dinamizadores regionais que a democracia só se efetiva por ações e relações que se dão na realidade concreta, em que a coerência entre o discurso e a prática é um aspecto fundamental. A participação não depende de alguém que "dá" abertura ou "permite" sua manifestação. Democracia não se concede, conquista-se.

Há de se considerar os determinantes econômicos, sociais, políticos e culturais mais amplos que agem em favor da tendência autoritária, enfrentados como manifestação, num espaço restrito. Não é suficiente permitir formalmente que a comunidade participe da administração da escola; é preciso que haja condições que propiciem essa participação. Neste sentido, considero importante o significado da participação para os envolvidos nesta experiência catarinense, que são:

1)paraa comunidade, participar da gestão de uma escola significa inteirar-se dos assuntos e opinar para o que, muitas vezes, se encontra despreparada; significa todo um aprendizado político e organizacional (participar de reuniões, dar opiniões, anotar, fiscalizar, cumprir decisões etc); significa mudar sua visão em relação ao que é direção de escola e ministrar aula, passando a não esperar decisões prontas a serem seguidas; significa, enfim, pensar a escola não como um organismo governamental, portanto externo, alheio, e sim como um órgão público que deve ser não apenas fiscalizado e controlado, mas dirigido pelos seus usuários;

2) para a direção e a equipe, estas vêm-se colocadas diante de tarefas eminentemente políticas, pois assumem o papel de dirigentes, técnicos e políticos. A abertura não acontece para um todo homogêneo e, sim, para uma população dividida, socialmente estratifícada e ideologicamente diferenciada; significa lidar com inúmeras expectativas e projetos políticos diferenciados;

3) para os alunos, a principal mudança refere-se à sua relação com os professores, especialistas e funcionários e com a direção: assumir 
sua parte de responsabilidade na direção da escola e do processo pedagògico, deixando de esperar soluções acabadas e de esperar apenas a punição como saida; compreender que transitar na difícil fronteira entre "liberdade e segurança" exige um compromisso com o projeto educacional, com os princípios e também com a visão mais global, menos fragmentária, da escola;

4) para os professores e especialistas, a oportunidade de conviverem e superarem conflitos originados dos embates interno e externo, na perspectiva de que o mais importante nessa relação participativa é o compromisso com o educando da escola pública, vendo nisso, a oportunidade de criar condições para uma ampla reformulação da prática escolar.

Admitir a democratização das relações tanto internas como externas, fortalece a escola como mediadora que pode contribuir para a formação de uma cidadania capaz de ajudar a transformar relações futuras, porém, ficando claro que não é a única responsável por esse processo de transformação. Por isso, a participação da direção, dos especialistas, dos professores, dos alunos, dos pais e dos funcionários na organização da escola, na escolha dos conteúdos a serem ensinados, nas formas de gestão, será tão mais efetivamente democrática à medida que os envolvidos nesse processo dominem o significado social das suas especificidades numa perspectiva de totalidade, isto é, que o significado social da prática de cada um contribua para ir aumentando a autonomia didático-administrativa e financeira da escola, para que melhor cumpram suas funções de construção e socialização do conhecimento.

Considero, ainda, que nesse processo de democratização da gestão escolar é indispensável que a escola respeite a realidade local, ao invés de continuar reduzindo o fazer educacional apenas tomando como base os moldes das classes médias urbanas, como é comum acontecer. Somente a partir de uma relação dinâmica e consciente com a comunidade, poderá ser garantida uma possibilidade para que a escola atue como um fator de mudança social.

Desde que se consiga a participação dos agentes educativos (direção, educadores, alunos, pais, funcionários e comunidade externa) 
nas decisões a respeito dos objetivos pedagógicos, bem como os meios adequados para implementar os objetivos, a escola tem melhores condições para pressionar os escalões superiores, no sentido de ir conquistando sua autonomia, aliada aos respectivos recursos financeiros e materiais. Neste sentido, parece mais difícil dizer não, quando a solicitação não é de uma pessoa, mas de um grupo organizado, que representa todos os segmentos e que está instrumentalizado pela conscientização que sua própria organização representa para a melhoria da qualidade de ensino.

Os resultados alcançados até o momento nessa experiência em andamento permitem sugerir investigações em nível micro, para melhor avaliar in loco os avanços e obstáculos dessa caminhada, o que traria contribuições significativas ao conhecimento da administração escolar, uma vez que a presente aparência, mesmo neste estágio, corrobora e amplia as possibilidades indicadas pelos recentes estudos a respeito da participação coletiva na gestão escolar, como uma das vias para a melhoria da qualidade do ensino e da consciência crítica da realidade social e para a construção de uma escola verdadeiramente pública, na busca da eliminação das desigualdades sociais.

Referências bibliográficas

ASSOCIAÇÃO DOS ADMINISTRADORES ESCOLARES DE SANTA CATARINA. [Relatórios dos Simpósios Catarinenses de Administração da Educação]. Florianópolis, set. 1992; set. 1993; set. 1994 e set. 1995.

BRASIL. Constituição. 1988. Constituição da República Federativa do Brasil. Brasília: Senado Federal, 1988.

CARDOSO, Jarbas José. Administração da educação: exigências frente ao novo que emerge. Florianópolis: Udesc/AAESC, 1995. mimeo. 
CARDOSO, Jarbas José. Nova ordem mundial e a gestão da educação. Rio de Janeiro: UFRJ, 1995. mimeo.

NUCLEO DOS ADMINISTRADORES ESCOLARES. Relatório de atividades de gestão compartilhada na escola pública. Florianópolis: AAESC, 1994. mimeo.

WITTMANN, Lauro Carlos, CARDOSO, Jarbas José (Org). Gestão compartilhada na escola pública. o especialista na construção do fazer saber fazer. Florianópolis: AAESC/Anpae-SUL, 1993.

Recebido em 25 de abril de 1995.

Jarbas José Cardoso, doutorando em Educação pela Universidade Federal do Rio de Janeiro (UFRJ), é professor de Planejamento Educacional do Centro de Ciências da Educação da Universidade do Estado de Santa Catarina (Udesc).

ipresent this article on behalf of all associates in order to socialize some experiences that the shared administration of the Association of School Admistrators of Santa Catarina (AAESC) has been developping in several regions. This program has been developed in association with the State Board of Education, the Municipal Board of Education, the Universities, and with others representative sections of the civil society. Because of that the purpose of this article is to present clearly the AAESC involvement with the Public School quality, having as mediation the shared administration that allows both the Association and Santa Catarina 's Educators, to propose practical administrative alternatives of the Pedagogic Project. Thus, I proceed to present the general effort in a regional levei, beginning with a brief description of ASASC. In item two I will discuss the preliminary theoretical principies, and in item three I will present some general aspectos of experiences in course. 
Cet article que je présente au nom de tous les associés vise à diffuser quelques-unes des expériences de Gestion Partagée que l'Association des Gestionnaires Scolaires de Santa Catarina (AAESC) est en train de développer dans plusieurs régions. Ce travail se fait en collaboration avec le Secrétariat à l'Educacion de l'Etat, avec les secrétariats à l 'education des municipalités, avec les universités et avec d'autres segments représentatifs de la société civile. Voilà pourquoi cet article a pour objectif d'exprimer avec clarté la préoccupation de l'AAESC avec la qualité de l'école publique. Dans cette action, elle a pour médiation la Gestion Partagée qui permet que l 'association tout autant que les éducateurs puissent proposer des alternatives pratiques de Gestion du Projet Pédagogique. Enfin, après un bref historique de l'AAESC, je présente une expérience d'effort collectif au niveau régional; dans la demiente partie, je discuterai des presuposés théoriques préliminaires; dans la troixiéme partie, je présenterai des expériences qui ont lieu en ce moment et, à la fin, quelques considérations générales.

Este artículo está presentado en nombre de todos los asociados, con el objetivo de manifestar algunas experiencias de la Gestión Compartida en la Asociación de los Administradores Escolares de Santa Catarina (AAESC) que viene realizando en conjunto con diversas regiones. Este trabajo que se hace en parceria con Ia Secretaria del Estado de Educación, secretarias municipales de educación, universidades o con otras instituciones representativas de la sociedad civil. Por esto, este artículo pretende expresar con claridad la involucración de la AAESC con la calidad de la escuela pública teniendo como mediación Ia Gestión Compartida que permite a la associàción como los educadores catarinenses, puedan proponer alternativas prácticas de administración al proyecto pedagógico. Por eso estoy presentando el esfuerzo colectivo en nivel regional, iniciando con un brevísimo histórico de la AAESC, en el párrafo dos, procurando una discusión de presupuestos teóricos preliminares, en el tercer párrafo, quedan presentadas las experiencias en los procesos y al final consideraciones generales. 